\title{
Um olhar sobre as relações entre movimentos sociais e Estados refundados nos Países Andinos, a partir de teorias participativas da democracia
}

\author{
Fabricio Pereira da Silva \\ Universidade Federal Fluminense (UFF), Angra dos Reis (Brasil). \\ Email: fabriciopereira@id.uff.br
}

\begin{abstract}
Resumo: Esse trabalho ${ }^{1}$ recorre às teorias participativas da democracia para compreender os diferentes papéis cumpridos pelos movimentos sociais na Venezuela, Bolívia e Equador a partir dos processos refundadores ocorridos nesses países. Espera-se que teorias participativas da democracia possam fornecer referenciais mais adequados para abordar as concepções de democracia que perpassam esses novos governos e instituições estatais redesenhadas. E a partir disso, melhor entender o papel reservado aos movimentos sociais nesses países se de protagonistas, atores secundários ou em processo de exclusão.
\end{abstract}

Palavras-chave: democracia participativa, Países Andinos, esquerda, Estados, movimentos sociais.

\section{Una mirada a las relaciones entre movimientos sociales y Estados refundados en los países andinos a partir de las teorías participativas de la democracia}

Resumen: Este trabajo recorre las teorías participativas de la democracia para comprender los diferentes papeles cumplidos por los movimientos sociales en Venezuela, Bolivia y Ecuador a partir de los procesos refundacionales ocurridos en esos países. Se espera que las teorías participativas de la democracia puedan proveer referencias más adecuadas para abordar las concepciones de democracia que atraviesan esos nuevos gobiernos e instituciones estatales rediseñadas. Para a partir de allí entender mejor el papel reservado a los movimientos sociales en estos países si de protagonistas, actores secundarios o en proceso de exclusión.

Palabras clave: democracia participativa, Países Andinos, izquierda, Estado, movimientos sociales.

\section{A view on the relationships between social movements and Refounded States in the Andean Countries, in participatory theories on democracy}

Abstract: This article draws upon participatory theories on democracy to understand the different roles played by social movements in Venezuela, Bolivia 
and Ecuador in the refounding processes occurring in these countries. It is expected that participatory theories on democracy can provide more appropriate references to address the conceptions of democracy that permeate these redesigned new governments and state institutions. And from that, to better understand the role reserved for social movements in these countries if protagonists, secondary actors or in the process of exclusion.

Key words: participatory democracy, Andean Countries, left, States, social movements.

$$
* * *
$$

A resposta oferecida aos problemas da democracia representativa e a possibilidade de democratização radical envolve a disposição de usar e trabalhar com muitas tradições diferentes de teoria política

(Hirst 1992: 16).

\section{Introdução}

Esse artigo recorre à teoria democrática que trata da participação para compreender os diferentes papéis cumpridos pelos movimentos sociais na Venezuela, Bolívia e Equador a partir dos processos refundadores ocorridos nesses países. Parto da premissa de que esses casos vêm sendo analisados (e muitas vezes condenados) a partir de parâmetros hegemônicos na teoria democrática ocidental: as abordagens que podem ser chamadas de elitistas ou procedimentais (cf. Macpherson 1978, Bobbio 2004). Pelo contrário, abordar esses casos a partir de teorias participativas da democracia (minoritárias na literatura especializada) poderia fornecer referenciais mais adequados e menos acusatórios para abordar as concepções de democracia que perpassam esses novos governos e instituições estatais redesenhadas. E a partir disso, melhor entender o papel reservado aos movimentos sociais nesses países se de protagonistas, atores secundários ou em processo de exclusão.

O artigo propõe com isso um exercício pouco realizado em relação à Venezuela, à Bolívia e ao Equador contemporâneos² : demonstrar como a utilização de marcos teóricos distintos permite a observação dos processos de refundação a partir de um prisma mais complexo. Não se espera negar que a partir de certas concepções de democracia os casos abordados apresentam problemas que podem ser considerados de envergadura, tais como a centralização de poderes no Executivo, a falta de accountability horizontal ou o excesso de reformas e guinadas decisórias (reduzindo a capacidade das políticas públicas, aumentando custos, etc.). No entanto, evidentemente esses problemas podem ser considerados centrais ou acessórios dependendo de como são observados. Alguns inclusive podem se mostrar falsos problemas. Mais do que isso, a partir de outras abordagens, novos êxitos e problemas podem vir à tona, aumentando a complexidade da análise e o acúmulo de dados o que deveria ser o horizonte das ciências sociais. 
Sugiro então que não há uma concepção universal de democracia: não há uma teoria nem modelo democrático universal, tampouco as teorias apresentadas nas próximas páginas o são. De modo geral, democracia deveria sempre ser tratada no plural, nunca no singular. Proponho avançar na observação desses casos a partir das teorias participativas da democracia já consideradas clássicas (apesar de contra-hegemônicas). Um passo adiante seria agregar as reflexões que já vêm sendo propostas pelos atores acerca dos processos nos quais estão inseridos, bem como de forma mais geral as reflexões sobre democracia realizadas a partir de prismas que se afastam da matriz ocidental do tema. Até que ponto isso ocorreria, por exemplo, com as formulações sobre democracia comunitária propostas por atores e movimentos indigenistas? No entanto, tais discussões superam os limites deste trabalho e o atual estágio das pesquisas que venho desenvolvendo. Serão certamente questões para futuros trabalhos.

Cabe um último esclarecimento acerca do que quero dizer com processos refundadores. Considero que nesses países estas esquerdas chegaram ao poder em meio a uma crise orgânica (com elementos políticos, culturais, sociais, econômicos), de decomposição mais radical da hegemonia expressada anteriormente e de chegada a uma situação de empate catastrófico. Nela, temporariamente as forças em disputa não conseguem impor-se e construir uma nova hegemonia (remeto a Gramsci). Não é somente com as insuficiências do modelo neoliberal (notada em toda a região) que essas crises se relacionam, é também com o esgotamento de formas de organização estatal, dominação social, baixa inclusão políticosocial e monopólio partidário, expressos em mais largas durações. Essas conjunturas específicas levariam a governos de propostas mais radicalizadas, que procuram ser refundadores de suas instituições e até certo ponto de suas configurações sociais e econômicas, enquanto chamo os outros casos mais moderados e limitados como o Brasil, o Uruguai e o Chile de renovadores de políticas públicas e defensores de novas ênfases ${ }^{3}$ (Pereira da Silva 2011). Assim, os novos governos da Venezuela, da Bolívia e do Equador levam a cabo transformações consideráveis. Mas seria uma longa discussão (que fugiria das intenções desse artigo) definir até que ponto os Estados refundados preservam características dos Estados anteriores, ou em que medida eles reproduzem padrões econômicos seculares (como o extrativismo, que se traduz em rentismo na Venezuela).

Apresento agora a estrutura do artigo. Na primeira parte, serão revisadas algumas ideias e discussões sobre participação na literatura especializada consideradas já clássicas. Na segunda parte, será apresentado de forma simplificada o que efetivamente houve até o momento de refundação institucional quanto a novos mecanismos de participação, procurando articular essa apresentação com ideias presentes nas teorias democráticas participativas. Finalmente, tratar-se-á do papel dos movimentos sociais nos processos refundadores, procurando relacionar diferentes concepções e ideias em torno da participação com o efetivo papel desempenhado pela sociedade organizada naqueles processos. Espera-se mostrar que há correlações entre o peso exercido pela sociedade organizada nas refundações 
e a prevalência de diferentes concepções acerca da participação popular (e desenhos institucionais relacionados), da própria noção de cidadania (se coletiva ou individual) e seus direitos, e do peso assumido pela ideia de nação.

\section{Participação: noção contra-hegemônica e polissêmica}

Pode-se afirmar que o conceito de participação só passa a fazer sentido (e mesmo a poder ser pensado) a partir do surgimento da democracia dos modernos, da nova versão de democracia em sua forma representativa. Antes disso, como se sabe, nos poucos lugares e momentos históricos onde emergiu, democracia era participação, dos (poucos) cidadãos na deliberação em assembleias e debates sobre os assuntos públicos da pólis helênica, da res publica romana, das cidades-Estado do renascimento no norte da Península Itálica. A democracia dos antigos ${ }^{4}$ era o que hoje se chamaria propriamente democracia direta. Assim, democracia e democracia direta significavam conceitualmente o mesmo, e a ideia de representação era considerada negativa algo que pode ser visualizado na insistência ateniense no sorteio em lugar do voto, quando havia a necessidade de se selecionar alguém para cumprir uma determinada função (Dahl 2001). A ideia de representação se associava historicamente a ambientes e instituições que em geral nada tinham a ver com qualquer referência à noção de democracia, tais como confederações ou as assembleias estamentais da Idade Média. Cabe recordar também que até o século XIX as teorias democráticas (em qualquer sentido) eram absolutamente minoritárias, algo submerso quase todo o tempo, emergindo em ocasiões determinadas.

A recorrente ideia de que a democracia era inviável em grandes territórios, em populações vastas e em sociedades complexas (como ainda se via em Jean-Jacques Rousseau) foi superada historicamente apenas pelo surgimento e consolidação de uma nova concepção e armadura institucional, calcadas na representação. Algo que poderia ser considerado parcialmente uma invenção dos Federalistas e dos debates da Constituição dos Estados Unidos da América. Mas deve-se recordar que não há qualquer referência a democracia na referida Constituição, e que a intenção majoritária dos pais fundadores era a de estabelecer um sistema representativo (com poderosas invenções conservadoras como o Senado e a Suprema Corte), não propriamente uma democracia no sentido clássico. As duas noções ainda não haviam se tocado, o que reforça a tese de que foram se mesclando mais exatamente ao longo do século XIX, mediante um processo fortemente alimentado pelo encontro (inédito e para nada tranquilo ou inexorável) de correntes do liberalismo com a democracia e aqui utilitaristas radicais como Jeremy Bentham, James Mill e seu filho John Stuart Mill devem ser mencionados.

Desde então, o liberalismo poderia até ser democrático (embora não necessariamente), mas a democracia não seria mais a mesma: agora seria sempre mais ou menos marcada pelo mercado capitalista e pelas leis da 
economia política clássica. Crawford Macpherson (1978) observa que a democracia, até seu encontro com o liberalismo, era pensada para sociedades sem classe (a Utopia de Thomas More) ou predominantemente de classe única (a sociedade de agricultores independentes de Thomas Jefferson). Somente então a democracia passou a ser algo adaptado a sociedades classistas (com a progressiva inclusão de diferentes classes na cidadania). Concomitantemente, o surgimento de um sistema representativo baseado em eleições passou a crescentemente hegemonizar a noção de democracia, ao ponto dos sinais se inverterem: democracia e democracia representativa passavam então a significar conceitualmente o mesmo. Representação por eleitos eleitos, diga-se de passagem, cada vez mais considerados representantes da consciência nacional e não delegados de seus eleitores (como em Edmund Burke) passou a estar no cerne da democracia que, em suma, manteve seu significado etimológico essencial de governo ou poder do povo, mas passou a nomear instituições, mecanismos e práticas radicalmente distintas. Participação e decisão direta foram sendo crescentemente consideradas como características de sociedades historicamente superadas, inviáveis na modernidade.

A ideia de democracia como democracia direta, como participação da cidadania nos assuntos públicos seguiu viva, mas agora em posição contra-hegemônica, periférica. A democracia em seu velho sentido apareceu ao longo do século XIX e princípios do XX em pensadores radicais, e um exemplo notável é a interpretação que Karl Marx em sua maturidade fez da Comuna de Paris, entendendo-a como a forma estatal finalmente descoberta do socialismo, calcada numa democracia comunal expressa no poder popular (Marx 2011). Bem como as recorrentes referências marxianas e marxistas a então nascente democracia representativa como burguesa ou ditadura da burguesia, guardando a utilização do conceito de democracia em sentido puro à futura sociedade comunista. Como Lenin o fez em $O$ Estado e a Revolução, pressupondo que democracia só era possível em sociedades sem classe, homogêneas, sem pluralidade de interesses materiais indicando assim que as reflexões democráticas da corrente marxista seguiram essencialmente preservando ao longo do século XX o traço essencial apontado por Macpherson nas teorias clássicas de democracia (um sistema adequado a sociedades sem classe ou de classe única).

Aquela referida ideia, agora periférica, assumiu alguma força e maior sistematicidade a partir do amadurecimento (e primeiros sinais de insuficiência e crise) do modelo majoritário de democracia contemporânea, nossa conhecida ideia minimalista de democracia (derivada das teorizações de Joseph Schumpeter em Capitalismo, Socialismo e Democracia, de 19425) enquanto mecanismo de seleção de elites, que Macpherson nomeou modelo de equilíbrio elitista pluralista:

pluralista porque parte da pressuposição de que a sociedade a que se deve ajustar um sistema político democrático é uma sociedade plural, isto é, uma sociedade consistindo de indivíduos, cada um dos quais é impelido a muitas direções por seus muitos interesses (...). É 
elitista naquilo que atribui a principal função no processo político a grupos auto-escolhidos de dirigentes. É um modelo de equilíbrio no que apresenta o processo democrático como um sistema que mantém certo equilíbrio entre a procura e a oferta de bens políticos (Macpherson 1978: 81).

A tese de que a democracia dos antigos poderia alimentar e se mesclar à democracia dos modernos começou a ganhar alguns adeptos. As expectativas nutridas por diversos teóricos minoritários a partir dos anos 1960 e 1970 se direcionaram a superar ou ao menos contrabalançar as concepções elitistas (schumpeterianas) de democracia. No entanto, não bastasse o conceito de democracia ser polissêmico, a ideia de participação também se apresentaria dessa forma sendo seu denominador comum (talvez o único) exatamente seu papel contra-hegemônico em relação às concepções majoritárias de democracia. Procurando dar alguma ordem aos debates do campo que chama de as outras teorias da democracia (e deixando claro entender que sua classificação não é a única possível), Gabriel Vitullo (2012) delimita três correntes teóricas que questionam as reflexões majoritárias sobre democracia:

1) Participacionismo: para essa corrente, democracia é mais propriamente um tipo de sociedade, não um sistema político. Advogase a expansão democrática a novos campos, como a família, a escola, o ambiente de trabalho e as forças armadas. Entende-se a participação como um bem em si mesmo, que adicionalmente pode levar ao autodesenvolvimento e à redução das desigualdades sociais. Aí Vitullo localiza autores como Macpherson, Carole Pateman, Peter Bachrach e as reflexões mais recentes de Robert Dahl ${ }^{6}$, deixando em aberto a filiação de Norberto Bobbio a essa corrente ${ }^{7}$;

2) Deliberacionismo: enfatizam a deliberação e o consenso, valorizando a expressão pública de valores e o intercâmbio permanente de razões mediante um processo dialógico e crítico, que formariam consensos ou ao menos interesses coletivos, indivíduos melhor informados e educados, bem como novas (e moralmente defensáveis) soluções. Na base dessas reflexões estão evidentemente as formulações de Jürgen Habermas, em sua valorização do diálogo num espaço público revigorado. Outros autores classificados por Vitullo nessa corrente seriam James Bohman, Joshua Cohen e Bernard Manin, entre outros;

3) Republicanismo cívico: aqui Vitullo agrupa autores como Hannah Arendt, Benjamin Barber e Sheldon Wolin, que propugnam um resgate das tradições das práticas democráticas e da vida cívica clássicas, dando centralidade ao conceito de cidadania ativa em uma república. Isso pode ser resumido na defesa de uma forma de cidadania mais rica, profunda e ativa a autêntica realização humana só é possível quando o indivíduo se torna cidadão e atua em uma comunidade livre a autogovernada (Vitullo 2012: 88) e de valores 
como bem comum, virtudes cívicas e espírito comunitário. Em suma, procura-se resgatar a ideia aristotélica do homem como animal político (que só se realiza enquanto integrante da polis), a noção ativa de liberdade (enquanto autogoverno) e a primazia do político e do público.

Apesar dessa gama de reflexões, deve-se constatar que as definições de democracia que Macpherson denominou de equilíbrio elitistas pluralistas seguiram exercendo um peso hegemônico (quase dominante) na academia, na opinião pública e nos desenhos de políticas públicas ao ponto de Boaventura de Sousa Santos falar em perda de demodiversidade, um empobrecimento ecológico dos saberes referentes aos conceitos e práticas democráticas, e caracterizar a democracia contemporânea como de baixa intensidade (Santos 2010; Santos, Avritzer 2009). Assim, a democracia representativa segue sendo praticamente sinônimo de democracia e tal redução segue sendo merecedora de críticas. Como advertiu Paul Hirst (1992), contestar o termo dominante parece ser suicídio político, mas tal contestação precisa ser feita, em nome da democracia. A noção dominante a democracia representativa como democracia serve para legitimar o grande governo moderno e para livrá-lo de praticamente todo controle (30).

\section{Novos mecanismos participativos e o que isso pode ter a ver com teorias participativas da democracia}

A referida noção dominante tem sido obrigatoriamente tensionada a partir dos discursos e experimentos levados a cabo pelos governos refundadores da Venezuela, Bolívia e Equador. Discursivamente, propugnam uma democracia participativa, protagônica ou comunitária. Os três governos apresentam noções heterodoxas de democracia (críticas à concepção liberal de democracia eminentemente representativa e procedimental), que associam à representação diversas concepções de participação, deliberação direta, comunitarismo e poder popular. Na prática, esses discursos foram traduzidos em transformações institucionais através do desenho e fomento de mecanismos e espaços de participação e deliberação direta. Cabe dizer que esses países também introduziram transformações nos mecanismos propriamente de representação, estendendo-os na forma de aumento da representação de gênero e indígena, bem como da introdução da representação em espaços onde anteriormente ela não existia como o Poder Judiciário. No entanto, deixo esses aspectos de fora dessa análise. Também não abordo diretamente formas localizadas de expansão da participação e da descentralização, como o estabelecimento de territórios autônomos indígenas, ou de elementos e organismos de participação e deliberação criados por governos subnacionais (apesar de eventualmente mencioná-los).

Pensando apenas no desenvolvimento de mecanismos e iniciativas a nível nacional, a lista já é extensa. Os mecanismos propriamente de demo- 
cracia direta introduzidos por esses regimes são basicamente: referendos para revogação e ratificação de leis constitucionais, bem como de decisões relativas à política externa (qualquer modificação constitucional deve ser ratificada, assim como decisões transcendentes relacionadas à perda de soberania nacional para organismos internacionais); revogação de todos os cargos eletivos; iniciativa de lei popular, e inclusive de convocação de assembleia constituinte. Exemplos disso são as ratificações das convocações de assembleias constituintes nesses países, e a posterior aprovação popular das novas constituições; bem como os diversos referendos revogatórios levados a cabo especialmente na Venezuela e na Bolívia, incluindo os dos próprios presidentes no primeiro por iniciativa popular (da oposição), no segundo do próprio presidente, em ambos os casos vencidos pelos mandatários.

Entretanto, aqui o foco será posto nos novos espaços de participação cidadã consolidados pelas novas constituições desses países. Além de fomentar a participação, estes novos mecanismos possuem funções de controle social, transparência, rendição de contas e combate à corrupção, através da instituição nos três países de novos poderes direcionados a isso, transformando a lógica liberal clássica de divisão do aparato estatal em três poderes (Executivo, Legislativo, Judiciário): a Função de Controle, Defesa da Sociedade e do Estado na Bolívia, a Função de Transparência e Controle Social no Equador, e o Poder Cidadão na Venezuela. Adicionalmente, vêm sendo desenvolvidas capacidades de cogestão, aí incluída a atuação no desenho de políticas públicas e elaboração de planos nacionais na Bolívia e no Equador, e mesmo a execução de obras, programas sociais, prestação de serviços públicos e gestão de empresas e políticas microlocais na Venezuela. Nos países estudados, sugiro haver uma combinação entre as instituições da democracia representativa, novas formas de participação e fenômenos mais próximos de uma democracia plebiscitária. Em certo sentido poderiam constituir expressões de demodiversidade, mas ao mesmo tempo das dificuldades contidas em sua realização.

Na Venezuela, o mecanismo de participação que adquire maior relevância nos últimos anos é o Conselho Comunal (CC), estruturado a partir de certo número de famílias organizadas num âmbito espacial microlocal ${ }^{8}$. Estes foram fomentados pelo Estado especialmente a partir de 2006, como mecanismo preferencial de participação popular no desenho e implantação de políticas públicas, e de maneira geral como meio de construção de uma democracia revolucionária e socialista (a partir de então o regime passou a defender uma democracia revolucionária e socialista, que englobaria a democracia participativa e protagônica consagrada na Constituição de 1999). A Lei Orgânica dos Conselhos Comunais (de 2006, modificada em 2009) os define como

instâncias de participação, articulação e integração entre os cidadãos, cidadãs e as diversas organizações comunitárias, movimentos sociais e populares, que permitem ao povo organizado exercer o governo comunitário e a gestão direta das políticas públicas e projetos orien- 
tados a responder às necessidades, potencialidades e aspirações das comunidades, na construção do novo modelo de sociedade socialista de igualdade, equidade e justiça social (Asamblea Nacional de la República Bolivariana de Venezuela 2009).

Os CC se estruturam a partir da realização periódica de assembleias locais (que são em última instância seus espaços decisórios), que estabelecem comitês dirigentes com distintas funções. Dedicam-se prioritariamente à articulação de organizações de base existentes e ao fomento de novas; elaboração de um plano de trabalho; controladoria social sobre projetos públicos; e mesmo ao eventual desenvolvimento e gestão de projetos públicos. Conjuntamente, são responsáveis pela participação direta nas decisões e na implantação de políticas públicas a nível comunitário, e relacionam-se diretamente com o Executivo nacional (Jungemann 2008), atualmente através do Ministério do Poder Popular para as Comunas e Proteção Social. Este pelo menos no princípio capacita e forma seus dirigentes (porta-vozes ou voceros), define parâmetros para seu funcionamento, avalia suas atividades, fomenta novos CC, e disponibiliza recursos financeiros e técnicos necessários para a realização de seus projetos, que devem ser aprovados por instâncias superiores.

Recentemente, tem havido um esforço para que a partir da reunião de vários CC se formem instâncias superiores denominadas comunas (consideradas em construção), que assumiriam o autogoverno em espaços maiores (mais próximos das dimensões de um bairro) e potencialmente assumiriam um caráter mais marcado de poder alternativo parcialmente sobreposto a instituições de representação municipais. Nesses novos espaços, começam a serem discutidos e articulados mais seriamente projetos produtivos comunitários (alimentícios, têxteis, artesanais, etc.), além de meios de transporte e de comunicação alternativa. A Lei Orgânica dos Conselhos Comunais também prevê a articulação das comunas em federações de comunas, o que aponta idealmente para uma construção piramidal potencialmente alternativa à geometria territorial baseada na mediação e na representação consideradas tradicionais.

Ademais, trata-se majoritariamente de participação focada na atuação da cidadania comum ou anteriormente desorganizada, apesar da participação de militantes de organizações sociais como os Comitês de Terra Urbana, de integrantes do Partido Socialista Unido da Venezuela (PSUV), etc. Devese notar, entretanto, que a participação não se restringe apenas a esse formato, estendendo-se a discussões mais temáticas para a elaboração e aprovação de políticas públicas importantes (como a Lei de Terras ou a recente Lei Orgânica do Trabalho). Vem sendo aventada também a possibilidade da ampliação da participação no ambiente de trabalho, o que tem sido tentado experimentalmente em empresas desprivatizadas (agora a meio caminho entre estatais e autogestionárias), através da instituição de comitês de fábrica com participação em decisões. Finalmente, deve-se observar que antes de 2005 foram testadas outras formas de participação, agora relegadas a um segundo plano ou abandonadas (Seabra, Pereira da 
Silva 2013).

Martorano (2011) mapeia toda a tradição conselhista na teoria socialista, desde a defesa de Marx da Comuna de Paris, passando pela sua centralidade na democracia operária em Gramsci e organização do proletariado em Luckács. Essa tradição conselhista se manifestará na experiência venezuelana a partir da pretendida virada socialista de 2004/2005, e remete em grande medida à reflexão socialista. Mas há aqui uma diferença essencial: a organização comunal projetada pela Revolução Bolivariana é basicamente calcada no território, não no local de trabalho adequado à tradição organizativa das últimas décadas naquele país, de movimentos de bairro, comitês de terra urbana, de gestão da água, etc. Nesse sentido, complementarmente pode ser enriquecedor se pensar no conselhismo para além da tradição socialista. Basta recordar a visão positiva que uma autora para nada socialista como Arendt (1988) nutre dos conselhos (remetendo aos distritos repúblicas elementares propostos por Jefferson no final de sua vida). Para a autora, os conselhos seriam um novo espaço para a liberdade, uma forma de governo inteiramente nova, piramidal, na qual a autoridade seria gerada em cada uma de suas camadas. Macpherson (anticapitalista, porém não socialista no sentido clássico) também propôs vagamente um sistema piramidal baseado em conselhos locais definidos territorialmente que delegariam funções às instâncias superiores representativas mas preservando sobre elas alta dose de controle.

Lentamente, no caso venezuelano vêm sendo propostos (e eventualmente testados) avanços no campo da autogestão em comunas e em algumas empresas tornadas públicas. Essa é uma proposta comum na tradição teórica da democracia participativa. Pateman (1992), por exemplo, defende a centralidade da participação no ambiente de trabalho, a autogestão especificamente na indústria a insistência na indústria evidentemente se justifica por se tratar de uma obra do final dos anos 1960 calcada na lógica das então sociedades industriais, e ligeiramente inspirada na experiência de autogestão iugoslava, e praticamente considera inviável a participação a nível nacional (no que se aproxima de Bobbio 2004). A democratização para essa autora ${ }^{9}$ avançaria quando conquistasse o ambiente de trabalho reflexão que parece presente de forma limitada e preliminar no caso venezuelano, mas como se verá está ausente nos experimentos bolivianos e equatorianos.

Por sua vez, o novo Estado boliviano apresentaria um amálgama mais plural de formas participativas, tendo como sua principal novidade o elemento da democracia comunitária associada a ideias de coletivismo, consenso mediante debate, assembleísmo e cooperativismo, mas também marcado por maior relação com movimentos sociais afins ao governo (articulados através do Vice Ministério de Coordenação com os Movimentos Sociais, subordinado ao Ministério da Presidência). A ideia se relaciona à concepção de um vivir bien ou suma kamaña (em aimara), que seria baseado na complementaridade de conhecimentos, num estado de vida integrado à natureza e baseado numa visão cosmológica de paridade do homem com 
ela, que levaria a uma sociedade de justiça social e ambiental. Estaria assim se constituindo assim uma democracia intercultural, sustentada

na existência das nações e povos indígena originário camponeses e das comunidades interculturais e afrobolivianas (...) com diferentes formas de deliberação democrática, distintos critérios de representação política e o reconhecimento de direitos individuais e coletivos, (...) [e] baseada na complementaridade da democracia direta e participativa, democracia representativa e democracia comunitária (Lei do Regime Eleitoral apud Colpari 2011: 5).

Essa referida complementaridade entre distintas formas de participação começou a tomar forma a partir da promulgação de duas leis em meados de 2010, a Lei Marco de Autonomias e Descentralização Andrés Ibáñez e a Lei do Regime Eleitoral. Mais especificamente, são quatro os espaços através dos quais vêm sendo concebida a participação. Local, a partir da descentralização que definiu quatro níveis administrativos e deliberativos subnacionais (nos quais se espera que exista abertura à participação): o departamental, o regional, o municipal e o indígena. Comunitário, num contexto de Estado Plurinacional que legaliza os referidos espaços autonômicos indígenas, ou territórios indígenas originários camponeses como são legalmente denominados. Corporativo, através da participação de organizações sociais em diversos espaços e fóruns de debates, por vezes mediados pelo referido Vice Ministério de Coordenação com os Movimentos Sociais. E setorial, através de órgãos consultivos, de transparência e controle estatal fomentados em cada ministério ou espaço governamental estatal através do Ministério de Transparência e Luta contra a Corrupção. Este ministério articula atividades em quatro eixos: aprofundamento da participação cidadã, transparência na gestão pública e direito de acesso à informação, eliminação da corrupção, e fortalecimento e coordenação institucional. Espera-se fomentar esses valores a partir de atividades de audiências públicas, capacitações e prestação de contas, com a participação de organizações sociais e originárias e de funcionários públicos, no âmbito dos distintos órgãos governamentais nacionais. De forma geral, essa divisão em quatro formas de participação se trata de um recurso argumentativo aqui esgrimido. Na prática, esses diferentes espaços se complementam, se cruzam e por vezes se chocam.

A valorização dos elementos comunitários na participação, como se viu, não é novidade em certas reflexões democráticas, conforme a classificação de Vitullo. A ênfase posta por uma corrente de autores na deliberação, no diálogo, no consenso e em valores da boa convivência pode ser reencontrada recorrentemente nas concepções e práticas da democracia comunitária (e de forma geral nas teses em torno da suma kamaña/sumak kawsay) presentes em movimentos sociais indígenas-campesinos, parcialmente transferidas para a institucionalidade boliviana particularmente nos níveis subnacionais e nos espaços autonômicos. A concepção de democracia comunitária prevê a formação de consensos e valores coletivos através da deliberação pública, e a geração de novas e melhores soluções. 
Adicionalmente, deve-se notar que elementos corporativistas e setoriais (participação de sindicatos e movimentos de minorias em temáticas específicas relacionadas a seus interesses diretos) vêm sendo levados adiante especialmente na Bolívia ${ }^{10}$. Mais uma vez, não se trata de uma estratégia alheia à tradição teórica participativa apesar da majoritária recusa ao corporativismo por parte da literatura acadêmica nas últimas décadas. Hirst (1992) defende a adoção de mecanismos corporativos semiinstitucionalizados articulados a um Estado progressivamente pluralista (fruto da crescente complexidade social e de maior deliberação): a representação corporativa dos interesses organizados pode fortalecer a democracia, no sentido de aumentar a influência popular sobre o governo (13, ênfase do autor).

Finalmente, no Equador, igualmente chama a atenção a pluralidade de formas (mais bem de experimentos) de participação. Poderiam ser utilizadas ao menos três entradas para abordar os diferentes espaços de fomento da participação nesse caso: o Conselho de Participação Cidadã e Controle Social (CPCCS); o Poder Executivo nacional; e o Sistema Nacional Descentralizado de Planificação Participativa (SNDPP).

O CPCCS é parte do que é considerado um novo poder do Estado equatoriano (além do Legislativo, Executivo, Judiciário e Eleitoral). Tratase de uma instituição formada por representantes da sociedade organizada (oficialmente sem vínculos partidários), com o intuito de incentivar os âmbitos de deliberação pública e participação política, combater a corrupção e estabelecer mecanismos populares de prestação de contas dos outros poderes estatais (Pernasetti 2010: 1). Seus participantes são selecionados para mandatos de cinco anos mediante concurso público, e sua estruturação poderia ser entendida, além de participação popular, como uma forma de estruturação de uma representação pós-liberal (ibid.: 19-20). O organismo agrega e fomenta diversos projetos e instituições voltadas à participação e desenvolvimento de projetos; à accountability vertical (fiscalização, transparência, prestação de contas); e à transparência e controle da corrupção. O CPCCS se estrutura a partir de uma direção formada por conselheiros, passando por secretarias executivas, e chegando ao fomento de iniciativas de participação (como Cabildos e Assembleias locais) e controle social (Controladorias e Observatórios Cidadãos). No entanto, o órgão vem encontrando diversas dificuldades para atuar, relativas à redução de seu orçamento, à dedicação excessiva a sua função de definidor das comissões cidadãs que devem realizar os concursos públicos para seleção de membros de instâncias estatais, às disputas internas entre conselheiros e a eventuais ingerências do Executivo em suas atividades.

Além desse novo poder estatal dedicado à participação, podem ser mapeadas diversas formas de participação através do Poder Executivo. Assim como na Bolívia, há no Executivo um espaço dedicado à articulação com a sociedade organizada (a Secretaria de Povos, Movimentos Sociais e Participação Cidadã, em tese também responsável por algumas atividades relativas ao fomento de participação e capacitação de lideranças). 
Apresentam-se espaços de participação em diferentes ministérios (mesas de diálogo e conselhos setoriais, de caráter consultivo e com representação de movimentos sociais). Vêm sendo desenvolvidas também as Redes Cidadãs, articulações de membros da sociedade civil e cidadãos comuns a nível local, regional e nacional, que esperam funcionar como articulação e legitimação nas relações entre Estado e sociedade ainda que preservem também funções de fomento da transparência, rendição de contas e conscientização popular.

Finalmente, deve-se referir ao SNDPP. De acordo com o que foi definido pela nova Constituição, vêm sendo instituídos conselhos de planificação participativa para a elaboração da planificação governamental desde as juntas paroquiais (nesses espaços de planificação local o processo já está mais estruturado e a cidadania adquire maior empoderamento), passando pelos demais níveis administrativos até chegar ao (pluri)nacional, culminando no Conselho Nacional de Planificação. Este tem diversas funções, sendo a principal a aprovação do Plano Nacional de Desenvolvimento, e suas eventuais retificações. Nota-se que essas chaves propostas são assim como no caso da Bolívia um recurso analítico: por vezes esses espaços e funções se cruzam, ora de forma complementar, ora concorrente. Trata-se, evidentemente, de espaços de disputa, com intencionalidades distintas, e ainda em processo de construção.

O discurso cidadão de Correa remete imediatamente à retomada na modernidade de valores e práticas pré-modernas agora adaptadas, a essência do republicanismo cívico. Nesse sentido, por mais paradoxal e impróprio que possa parecer à primeira vista, pode ser útil recorrer mais uma vez a Arendt. Para a autora, não se deveria confundir direitos civis com liberdade política, ou a comparar essas preliminares do governo civilizado com a própria essência de uma república livre. Pois, falando de uma maneira geral, liberdade política ou significa participar do governo ou não significa nada (Arendt 1988: 174-175). Participar pode ser entendido por expressão, discussão e decisão, as quais, num sentido positivo, são as atividades da liberdade (ibid.: 188). E ninguém poderia ser chamado livre se não experimentasse a liberdade pública, ou ser chamado feliz se não experimentasse a felicidade pública. Ou seja, ninguém poderia ser feliz ou livre sem participar da política e estar integrado à polis. Esse cidadão ideal numa república ideal é um elemento central no discurso de Correa, bem como na concepção da maioria dos mecanismos de participação equatorianos, calcados em cidadãos pulverizados participativos organizados em redes, conselhos e assembleias na base; e complementados sintomaticamente por cidadãos/conselheiros exemplares, responsáveis pelo fomento da participação, transparência e civismo (os membros do CPCCS).

Por fim, nos três países nota-se que se desenvolve capacidade de decisão popular a nível barrial e no máximo municipal, enquanto nos níveis superiores a participação assume um caráter consultivo, e características próximas da representação (através de lideranças locais ou de organizações reconhecidas pelos governos). Nesse sentido, esses espaços de participação 
estão longe de superar a recorrente deficiência das teorias e mecanismos participativos em transcender o local o que constitui provavelmente seu grande desafio, e seu maior flanco para críticas por parte de seus detratores. $\mathrm{O}$ quadro abaixo apresenta resumidamente algumas características prevalecentes em cada caso nacional.

\section{Quadro 1: Mecanismos de participação nos processos de refundação}

\begin{tabular}{|c|c|c|c|}
\hline Caso & Nivel & Capacidade & Atores privilegiados \\
\hline Venezuela & $\begin{array}{c}\text { Local a } \\
\text { microlocal }\end{array}$ & $\begin{array}{c}\text { Decisão, gestão de políticas e de meios } \\
\text { de produção }\end{array}$ & Atores coletivos \\
\hline Bolívia & Nacional a local & $\begin{array}{c}\text { Consulta a nível nacional, consulta e } \\
\text { decisão a nivel regional e local }\end{array}$ & Cidadão \\
\hline Equador & Nacional a local & $\begin{array}{c}\text { Consulta a nível nacional, consulta e } \\
\text { decisão a nivel regional e local }\end{array}$ & \\
\hline
\end{tabular}

Fonte: elaboração própria

\section{Movimentos sociais e participação nos Estados refundados}

Após essa rápida passagem por propostas participativas e suas possíveis articulações com as instituições testadas na Venezuela, Bolívia e Equador, deve-se investigar de que forma essa reflexão poderia lançar luz sobre a relação desses governos com a sociedade civil organizada. A principal pergunta é qual o papel reservado aos movimentos sociais nas concepções e nos espaços de participação desenvolvidos nesses países. Os movimentos de protesto configurados na Venezuela, Bolívia e Equador desde os anos 1980 se caracterizaram muitas vezes pela maior pluralidade, pulverização, estruturação em redes e territorialização (o barrio ${ }^{11}$ e os Comitês de Terra Urbana $^{12}$ venezuelanos, os sindicatos rurais ${ }^{13}$ bolivianos e equatorianos, ayllus $^{14}$ e juntas vecinales ${ }^{15}$ bolivianas). Em momentos como o Caracazo venezuelano (1989) e a derrubada do presidente Lúcio Gutierrez no Equador pelo movimento dos foragidos ${ }^{16}$ (2005), a expressão semiespontânea foi norma. Já no caso dos cocaleiros bolivianos, manifesta-se forte coesão grupal e senso de coletividade. Assim, apesar de algumas características comuns, nota-se a diversidade de experiências. Deve-se analisar como essa diversidade se inseriu primeiramente no processo de proposição de uma alternativa hegemônica em suas sociedades, e posteriormente como vem participando dos referidos processos de transformações. É provável que a natureza da relação entre as novas lideranças políticas e configurações estatais por um lado, e os novos movimentos sociais por outro, esteja no centro das características próprias assumidas por cada processo.

Seguindo as sugestões de Maneiro (2006), é possível relacionar as transformações nas formas de vinculação do Estado com a sociedade civil como elemento central, embora não unívoco, de explicação do surgimento dos movimentos sociais nos últimos anos em nossa região (107). Nesse 
sentido, o crescimento das mobilizações sociais e surgimento de novas subjetividades coletivas autônomas nos três países analisados a partir da segunda metade dos anos 1980 estariam relacionados ao fim do padrão até então vigente de cooptação/repressão. No período anterior, instituiu-se nesses países com maior ou menor intensidade entre o Estado e setores mais organizados da classe operária e do campesinato uma relação que se movia pendularmente entre dois polos: cooptação desses setores, constituídos em atores políticos subalternos; ou repressão pura e simples. Esse padrão se manifestava na forma de aliança Estado e partidos tradicionais/trabalhadores na Venezuela, e Estado/campesinato na Bolívia e no Equador, superadas pelas crises econômicas e implantação do neoliberalismo dos anos 1980 e 1990.

Na sequência, seria igualmente possível analisar o papel e características atuais dos movimentos sociais nos processos de refundação a partir de como as relações Estado/sociedade vêm sendo reconstruídas. Na Venezuela, pode-se sugerir que os movimentos sociais (pelo menos os de maiores dimensão e organização) não foram os artífices e sustentáculos do processo desde o principio, tendo alguns deles estado abertamente na oposição desde o primeiro dia como boa parte dos movimentos estudantil e sindical. A exceção se deu em momentos pontuais, como a relativa participação em processos eleitorais e no contragolpe em 2002 no qual organizações barriais (estas sim com razoável incidência no processo ao longo de seu desenvolvimento) rapidamente se mobilizaram em defesa do regime. Com isso se relacionaria certa impositividade em princípio das políticas chavistas (com sentido de cima para baixo), inclusive participando da gestação de novos movimentos sociais. Seguindo a sugestiva terminologia de Mirza (2006), que classifica a relação Estado/movimentos sociais a partir das categorias de reflexo-dependência, autonomia moderada e autonomia radical, nota-se na Venezuela certa oscilação dos movimentos entre a primeira e a segunda forma (que derivariam na prática em apoio aberto ou crítico ao Estado).

Já a Bolívia constituiria um caso distinto, na medida em que movimentos sociais fortemente estruturados, aliados entre si a partir de redes regionais e nacionais e construtores de um projeto contra-hegemônico mais sólido efetivamente se constituíram em artífices e sustentáculos do processo de refundação tendo organizado para isso verdadeiras rebeliões ${ }^{17}$ ao longo da construção dessa alternativa contra-hegemônica. Isso se relacionaria à aproximação maior entre Estado e movimentos, e a uma maior relação de mão dupla (de cima para baixo, mas também de baixo para cima), especialmente nos primeiros anos de governo ${ }^{18}$ configurando até certo ponto uma relação de rede entre Estado, partido e movimentos sociais, mas obviamente com a crescente predominância do primeiro. No entanto, nessa relação mais dialógica, os movimentos preservariam parte razoável de sua autonomia em relação ao Estado (e ao partido). Recentemente, alguns deles vêm assumindo posições mais críticas, flutuando entre a autonomia moderada setores da Central Operária Boliviana, COB, como mineiros e sindicatos de camadas médias e a autonomia radical grupos indígenas do Oriente, agregados em torno de propostas preservacionistas e autonomistas mais 
radicais, em especial da preservação do Território Indígena e Parque Nacional Isiboro-Secure (TIPNIS), agora que elementos desenvolvimentistas vêm mais abertamente predominando na direção do processo.

Finalmente, o Equador constituiria um caso curioso, na medida em que no período anterior à ascensão de Correa se constituiu um movimento contra-hegemônico indigenista (com algumas características semelhantes ao processo desencadeado na Bolívia), centralizado na Confederação de Nacionalidades Indígenas do Equador (CONAIE). No entanto, por razões diversas entrou em crise antes de efetivamente se impor como alternativa de poder ${ }^{19}$. Enquanto isso, Correa chegou ao poder em meio a um refluxo da conflitividade social (Ramírez Gallegos 2010), apostando na cidadania desorganizada, e assumindo-se como tradutor dos anseios de um movimento opositor difuso e semiespontâneo, um amálgama de setores oriundos de diversas correntes de esquerda, de cidadãos independentes e de organizações e ONGs que lutavam por ética na política e contra a partidocracia, muitos dos quais tomaram parte no movimento cidadão que forçou a renúncia de Lúcio Gutierrez. Ou seja, num processo com algumas características semelhantes ao ocorrido na Venezuela.

No Equador, as novas instituições do Estado assumem características verticalistas no diálogo com movimentos e setores mais pulverizados, enquanto os movimentos sociais mais organizados e de larga trajetória lhe fazem oposição aberta com exceção do processo constituinte, que teve participação significativa das organizações sociais. Isso explica e se relaciona com os valores cidadãos da revolução (Revolución Ciudadana), que preza a meritocracia, a universalidade e a participação individual, e tende a desvalorizar as mediações, acusando-as de particularistas ou corporativistas. Nota-se mais recentemente um esforço governamental em fomentar novos movimentos sociais afins em diversas áreas (como camponeses e estudantes), o que gera um panorama de organizações sociais divididas entre a autonomia radical e a reflexo-dependência em relação ao Estado. Em suma, Correa foi

eleito como alternativa tanto à velha oligarquia quanto à nova direção popular, pelo que chega ao poder politicamente isolado. (...) A nova Constituição equatoriana é muito avançada, garante o reconhecimento de direitos indígenas e cria muitas formas de participação popular, mas o presidente está enfrentado com uma parte substantiva do movimento indígena na visão do desenvolvimento e da representação política. $\mathrm{O}$ avanço simbólico não se traduz até aqui em democratização para os de baixo devido a esta peculiar confrontação de projetos (Olvera, Chaguaceda 2010: 3).

Isso é denotado na relação difícil (para não dizer belicosa) de Correa com os principais movimentos sociais do país: indigenistas, ambientalistas e boa parte dos coletivos feministas. Isso ficou evidente quando o presidente afirmou que, após a derrota (ao menos parcial) das oligarquias antipátria, seu novo inimigo passava a ser o esquerdismo, o ecologismo e o indigenismo infantil: 
Sempre dissemos que o maior perigo para nosso projeto político, uma vez derrotada sucessivamente nas urnas a direita politica, era o esquerdismo, ecologismo e indigenismo infantil. Que lástima que não nos equivocamos! (...) os novos reacionários são precisamente aqueles fundamentalistas ecológicos, e eu acrescentaria, aquelas supostas organizações sociais que não representam ninguém, mas se comportam como se representassem a todos (Discurso de 19/01/2009 apud Ordoñez 2010: 89).

Assim, quanto ao papel atual dos movimentos sociais, estes tenderiam a encontrar maior espaço para atuação no caso boliviano, ainda que com a intermediação do Movimento ao Socialismo (MAS) especialmente no que tange às políticas agrárias (Do Alto 2011). Aqui os movimentos sociais parecem ainda preservar razoáveis graus de autonomia em relação ao Estado, com o qual negociam, realizam acordos, mas ao qual aparentam não se submeter por vezes o contestam, o influenciam e alguns o fazem oposição aberta. Quanto à Venezuela, a equação pode se inverter, especialmente a partir de 2006, quando o Estado, além de promover a participação e a construção de movimentos sociais como fez desde o princípio do processo, passou a tentar centralizar a participação através dos CC, em relação direta com o Executivo. Naquele país, os movimentos sociais progressistas tenderiam a assumir assim posições de reflexo-dependência ou no máximo de autonomia moderada em relação ao Estado. Por fim, no Equador, pelas características de Correa e sua base de apoio, poder-se-ia sugerir uma tendência de aproximação com a trajetória venezuelana, com relações mais verticalizadas e esforços governamentais por gerar divisões no seio das organizações sociais. Além disso, em ambos os casos os espaços de participação se voltam majoritariamente à participação do cidadão comum em novos órgãos (em geral constituídos pelo Estado), evitando mediações, sejam partidárias, sejam de movimentos sociais e não à participação/ representação de organizações sociais, como parece prevalecer na Bolívia. As diferentes modalidades de articulação entre Estados refundados e movimentos sociais poderiam ser resumidas conforme o quadro abaixo.

\section{Quadro 2: novas relações entre Estado e movimentos sociais}

\begin{tabular}{|c|c|c|c|}
\hline Caso & $\begin{array}{c}\text { Peso MMSS no } \\
\text { processo }\end{array}$ & $\begin{array}{c}\text { Iniciativa nas relações } \\
\text { Estado/MMSS }\end{array}$ & $\begin{array}{c}\text { Posicionamento MMSS em relação ao } \\
\text { Estado }\end{array}$ \\
\hline Venezuela & Fraco a médio & Maior iniciativa estatal & $\begin{array}{c}\text { Reflexo-dependência a autonomia } \\
\text { moderada }\end{array}$ \\
\hline Bolivia & Forte & Equilibrio relativo & Autonomia moderada a radical (oposição) \\
\hline Equador & Fraco a médio & Maior iniciativa estatal & $\begin{array}{c}\text { Reflexo-dependência a autonomia radical } \\
\text { (oposição) }\end{array}$ \\
\hline
\end{tabular}

Fonte: elaboração própria, com referências à terminologia de Mirza (2006)

Deve-se afirmar, antes de tudo, que nos três países houve uma retomada do Estado, após anos de políticas neoliberais. Além disso, enquanto nos governos anteriores a relação entre Executivos e movimentos sociais era conflituosa e estes em sua grande maioria estruturavam suas identida- 
des combatendo aqueles e suas políticas, agora há relações mais próximas em muitos dos casos, levando por vezes a crises e reconfigurações identitárias. Mas dito isso, podem ser apontadas diferenças caso a caso. Nota-se que a relação Estado/sociedade na Venezuela e no Equador se apresenta de forma distinta à da Bolívia. Nos primeiros, o Estado assume maior iniciativa desde o início do processo, aprofundando a participação em diversos níveis e aspectos, mas raramente transferindo capacidade decisória quanto ao desenho de políticas públicas nacionais mas sim barriais no caso venezuelano. Já na Bolívia, o Estado reformulado parece mais permeável à pressão e participação da sociedade (organizada), e aqui a iniciativa parece ainda estar um pouco mais compartilhada, pelo menos com as organizações sociais que assumem desde o princípio posições centrais no processo de transformação, notadamente os cocaleiros enquanto outros movimentos e sindicatos mais periféricos vão sendo afastados do núcleo decisório, assumindo uma posição mais autônoma ou em alguns casos abertamente oposicionista.

Nesse sentido, coerentemente os discursos e mecanismos de participação na Venezuela e no Equador privilegiam a atuação da cidadania pulverizada em processo de organização nos espaços de participação desenhados pelo Estado. O conselhismo piramidal, pertencente à tradição socialista, mas igualmente proposto por alguns autores participacionistas (como Macpherson) ou do republicanismo cívico (como Arendt), é central no caso venezuelano. Aqui o cidadão/militante popular chavista assume primazia, e se expressa na comuna, no bairro, nas brigadas eleitorais, mais recentemente no partido. Já no caso equatoriano, o indivíduo almejado não é exatamente o do modelo liberal (crítica comum recebida pela Revolução Cidadã por parte de movimentos sociais oposicionistas à sua esquerda). Sugiro ser mais propriamente o cidadão ativo na polis, republicano, de virtudes cívicas dada a ênfase na ética, no combate à corrupção, no resgate de valores, desde os primeiros dias de atuação pública de Correa e seu movimento. O paralelo com o republicanismo cívico, como já foi dito, parece evidente nesse caso. Em suma, o cidadão correísta é o republicano, não o utilitarista liberal. Ambos os modelos podem receber críticas enquanto tipos ideais, abstratos, sem concretude. Mas é importante não confundir as referências das quais se parte.

Mas o que importa frisar para os propósitos desse trabalho é que nesses dois casos os movimentos organizados encontram menor espaço de atuação. O que é coerente, aliás, com dois autores mencionados logo acima, Macpherson e Arendt. Em suas reflexões, a cidadania organizada tem pouco (no primeiro autor, que aceita no limite a presença de partidos) ou nenhum (no pensamento arendtiano, remetendo à aversão ao faccionalismo típica da democracia dos antigos) espaço para atuar. Já no caso boliviano, a participação da sociedade organizada é francamente alimentada, e encontra mais canais de diálogo e espaços de consulta (mas não exatamente de decisão) no Estado. E deliberação, consenso, faccionalismo e corporativismo são temas recorrentes nesse caso alguns deles de larga tradição na história boliviana. 
Em suma, a cidadania coletiva parece ser mais valorizada na Bolívia, em comparação com a Venezuela e o Equador nos quais o cidadão individual (militante, ativo) assume primazia nos mecanismos de participação. Adicionalmente, acima dos indivíduos (organizados ou não), a subjetividade coletiva nação/pátria se destaca nos dois últimos países, em comparação com o caso boliviano no qual a plurinacionalidade (pelo menos em princípio) através do indigenismo se impôs como ideia-força apesar de crescentemente a tradição nacional-popular reelaborada vir assumindo maior espaço.

Com tudo isso, espera-se ter ao menos avançado na direção de uma compreensão mais complexa dos casos estudados, recorrendo a teorias participativas da democracia que em certa medida já podem ser consideradas clássicas. Como qualquer teoria pensada a partir e para outros contextos, aplicar tais teorias a nossos casos de estudo pode levar à perda parcial de poder explicativo, e ao menos à necessidade de realizar algumas adaptações. No entanto, considero que recorrer a tais paradigmas enriquece a análise do que os governos da Venezuela, da Bolívia e do Equador vêm procurando fazer na última década em termos de redesenho das instituições democráticas, e como eles vêm se relacionando com movimentos sociais. Pode-se perceber, por exemplo, problemas e limitações dessas instituições que seriam negligenciados a partir de um olhar baseado nas teorias elitistas da democracia. Eventuais restrições à participação dos atores coletivos nas decisões em especial se estes não são governistas é o que salta aos olhos imediatamente. 


\section{Notas}

${ }^{1}$ Trabalho apresentado em versão preliminar no XVI Congresso Brasileiro de Sociologia (10 a 13 de setembro de 2013, Salvador).

${ }^{2}$ Há exceções como, por exemplo, os diversos trabalhos de Steve Ellner, Marta Harnecker e Boaventura de Sousa Santos sobre esses casos de estudo.

${ }^{3}$ Com a seguida chegada ao poder de partidos, movimentos e lideranças de esquerda na América Latina, a literatura especializada começou logo a elaborar tipologias (desde Aristóteles, uma velha tradição politológica) para explicá-la. A mais comum é a que sugere a existência de duas esquerdas, uma socialdemocrata ou democrata e outra populista ou autoritária, proposta por alguns estudiosos com intenção quase sempre normativa, em que a primeira é vista como uma esquerda boa e a outra como má. Minha expectativa era propor uma classificação que se afastasse das dicotomias defendidas por grande parte da literatura especializada, e para elaborá-la parti do pressuposto de que, num sentido mínimo, todas essas esquerdas são democráticas, e recusei, por outro lado, conceitos polissêmicos e acusatórios como o de populismo. Acredito que esses não constituem eixos apropriados para estruturar uma tipologia dessa natureza, sendo mais interessante destacar a gestação de projetos distintos, que se explicam pelas diferenças entre os atores e organizações, mas também por conjunturas, institucionalidades e temporalidades distintas. A diferenciação proposta procura não ser normativa, possui um caráter dinâmico, parte de bases distintas e reconhece as semelhanças entre os casos.

${ }^{4}$ Norberto Bobbio utilizava recorrentemente essa distinção, inspirado nas expressões liberdade dos antigos e liberdade dos modernos cunhadas por Benjamin Constant.

${ }^{5}$ Mais precisamente os capítulos 21, 22 e 23 do longo livro (cf. Schumpeter 1976).

${ }^{6}$ Não resta dúvida que diversos trabalhos de Dahl desde os anos 1970 podem ser classificados como participacionistas, desde o momento em que o autor começou a explorar as possibilidades de expansão democrática para além de sua definição mínima de poliarquia. Cuja formulação, aliás, sintomaticamente denotava sua recusa em ceder o honroso termo democracia aos sistemas pluralistas realmente existentes estratégia que abandonou mais tarde ao propor o conceito (mais acomodatório) de democracias poliárquicas. No entanto, Dahl não avançou além da tese da participação como algo que deveria se restringir ao âmbito local.

${ }^{7}$ A filiação de Bobbio a essa corrente é no mínimo polêmica. Torna-se difícil concordar com ela, na medida em que o autor afasta a participação do âmbito da política em qualquer nível, preservando uma definição procedimental e mínima de democracia como ele próprio admite. Para Bobbio, a expansão da democracia deveria ocorrer em outros âmbitos, econômico-sociais: a escola (e a universidade) e o local de trabalho. Deve-se recordar que a definição de política do autor é igualmente mínima, restrita às relações dos indivíduos e grupos com o Estado.

${ }^{8} 150$ a 400 famílias nas áreas urbanas, 10 a 20 famílias nas áreas rurais e 10 famílias nas comunidades indígenas.

${ }^{9} \mathrm{E}$ para certa tradição socialista autogestionária, para algumas correntes anarquistas e também para autores insuspeitados como Bobbio. 
${ }^{10}$ Aliás, um traço presente recorrentemente em sua história, principalmente na tradição nacional-popular que desembocou na Revolução de 1952 e se desenvolveu pelo menos até a ofensiva neoliberal a partir de 1985.

${ }^{11} \mathrm{O}$ que se chamaria favela no Brasil ou villa miseria na Argentina. Associações de moradores desses bairros mais pobres (especialmente de Caracas) assumiram um papel importante nas últimas décadas.

${ }^{12}$ Os Comitês de Terra Urbana são organizações sociais dedicadas à reivindicação de reforma urbana visando a ocupação e legalização de terras urbanas. Vêm participando dos espaços de participação desenvolvidos desde o Estado, mas buscando preservar autonomia.

${ }^{13}$ Os sindicatos rurais perderam em parte sua anterior associação com a identidade camponesa, passando a combiná-la com uma renovada e modernizada identidade originária (Soares 2009), na qual o território assume um aspecto de maior centralidade. Esses sindicatos constituíram na Bolívia uma rede nacional denominada Confederação Sindical Única de Trabalhadores Camponeses da Bolívia (CSUTCB), base da fundação do MAS. Para um estudo circunstanciado desse movimento boliviano, bem como dos citados nas próximas notas, conferir García Linera, León, Monje (2008).

${ }^{14}$ Estruturas indígenas comunitárias com elementos familiares estendidos e territoriais permanências e releituras de estruturas sociais pré-colombianas (basicamente aimaras, quéchuas e urus). Elas servem hoje de identificação e delimitação para movimentos étnicos, como o Conselho Nacional de Ayllus e Markas do Qullasuyu (CONAMAQ).

${ }^{15}$ Associações locais de moradores, que tiveram participação nas mobilizações contra a privatização da água e do gás nos anos anteriores à chegada do MAS ao poder. Manifestaramse principalmente em El Alto.

${ }^{16}$ Movimento de protestos semiespontâneos, formado majoritariamente pela juventude e camadas médias, e caracterizado pela convocação de mobilizações a partir de novas tecnologias de comunicação. Seus participantes foram chamados de foragidos pelo presidente, e acabaram assumindo a alcunha.

${ }^{17}$ A Guerra da Água em 2000, com o intuito de bloquear os projetos neoliberais de privatização da distribuição de água; a Guerra do Gás em 2003, com a intenção de nacionalizar a exploração de gás natural, bem como bloquear sua exportação para os EUA através de um gasoduto que passaria pelo Chile (que o privou de sua saída para o mar na Guerra do Pacífico no século XIX), causando a queda do presidente Sánchez de Lozada; e a derrubada do presidente Carlos Mesa em 2005, que relutava em levar adiante o processo de nacionalização do gás nos termos defendidos pelas organizações sociais.

${ }^{18}$ Um elemento que deve ser mencionado como forma de relativizar parcialmente essa argumentação é lembrar que se as organizações sociais perfuram o Estado, este último também estatiza as direções sociais, com um pé em suas organizações e outro em diversos cargos públicos (Do Alto 2011: 106).

${ }^{19} \mathrm{O}$ movimento indígena chegou a estruturar a principal força de esquerda do país antes da chegada de Correa ao poder (e uma das forças superadas por ele em sua ascensão meteórica): o Movimento de Unidade Plurinacional Pachakutik Novo País (MUPP-NP). As dificuldades 
Polis, Revista Latinoamericana, Volumen 12, $N^{\circ}$ 36, 2013

do MUPP-NP, entre outros fatores, devem-se ao seu apoio ao golpe de 2000 contra o presidente Jamil Mahuad, que pôs em questão a vocação democrática do partido. Em sua decadência deve ter pesado também o apoio em posição subalterna em 2002 à candidatura de Lúcio Gutierrez e aos primeiros meses de seu governo, que assumiu uma política neoliberal em contradição ao que havia proposto em sua campanha. O partido logo se afastou do governo. No entanto, sua imagem de outsider (importante na ascensão de esquerdas em países que vivenciaram colapsos de suas instituições e sistemas partidários) certamente foi abalada. 


\section{Referências bibliográficas}

Arendt, Hannah (1988), Da Revolução, Ática, São Paulo.

Asamblea Nacional de la República Bolivariana de Venezuela (2009), Ley Orgánica de los Consejos Comunales, s. ed., Caracas.

Bobbio, Norberto (2004), O futuro da democracia, Paz e Terra, São Paulo.

Colpari, Otto (2011), “La nueva participación ciudadana en Ecuador y Bolivia. ¿Resultado de la lucha del movimiento indígena-campesino?”, en Nómadas. Revista Crítica de Ciencias Sociales y Jurídicas n. especial América Latina.

Dahl, Robert (2001), Sobre a democracia, UnB, Brasília.

Do Alto, Hervé (2011), "Un partido campesino en el poder. Una mirada sociológica del MAS boliviano”, en Nueva Sociedad n. 234.

García Linera, Álvaro (coord.), León, Marxa Chávez, Monje, Patricia Costas (2008), Sociología de los movimientos sociales en Bolívia, Diakonia, Oxfam, Plural, La Paz.

Hirst, Paul (1992), A democracia representativa e seus limites, Jorge Zahar, Rio de Janeiro.

Jungemann, Beate (2008), “Organizaciones sociales y anclaje territorial. Escenarios y componentes de la transformación socio-territorial y local en Venezuela”, en Cuadernos del CENDES n. 67.

Macpherson, Crawford (1978), A democracia liberal. Origens e evolução, Jorge Zahar, Rio de Janeiro.

Maneiro, María (2006), “Movimentos sociais e Estado: uma perspectiva relacional”, en Domingues, José Maurício, Maneiro, María (orgs.), América Latina hoje, Civilização Brasileira, Rio de Janeiro.

Martorano, Luciano Cavini (2011), Conselhos e democracia. Em busca da participação e da socialização, Expressão Popular, São Paulo.

Marx, Karl (2011), A guerra civil na França, Boitempo, São Paulo.

Mirza, Christian Adel (2006), Movimientos sociales y sistemas políticos en América Latina, CLACSO, Buenos Aires.

Olvera, Alberto, Chaguaceda, Armando (2010), “¿Hay democracia participativa en los países del ALBA?”, en Envío n. 334.

Ordoñez, Pilar Pérez (2010), “El Presidente Rafael Correa y su política de 
redención”, en Ecuador Debate n. 80.

Pateman, Carole (1992), Participação e teoria democrática, Paz e Terra, Rio de Janeiro.

Pereira da Silva, Fabricio (2011), Vitórias na crise. Trajetórias das esquerdas latino-americanas contemporâneas, Ponteio, Rio de Janeiro.

Pernasetti, Fernanda (2010), “Agendas de reforma e aprofundamento da democracia na América do Sul: um primeiro olhar sobre o Conselho de Participação Cidadã e Controle Social do Equador”, en Observador Online n. 7.

Ramírez Gallegos, Franklin (2010), “Desencuentros, convergencias, polarización (y viceversa). El gobierno ecuatoriano y los movimientos sociales”, en Nueva Sociedad n. 227.

Santos, Boaventura de Sousa (2010), "Para una democracia de alta intensidad", en Ecuador Debate n. 80.

Ídem, Avritzer, Leonardo (2009), “Para ampliar o cânone democrático”, en Santos, Boaventura de Sousa (org.), Democratizar a democracia: os caminhos da democracia participativa, Civilização Brasileira, Rio de Janeiro.

Schumpeter, Joseph (1976), Capitalism, Socialism and Democracy, Harper Colophon Books, Nova Iorque.

Seabra, Raphael Lana, Pereira da Silva, Fabricio (2013), "Via Bolivariana: de onde vem, para onde vai”, en Revista de Estudos e Pesquisas sobre as Américas, v.7, n. 1.

Soares, Alice (2009), “A emergência das identidades étnicas na Bolívia contemporânea. Processos e atores”, en Domingues, José Maurício, Mota, Aurea, Soares, Alice, Pereira da Silva, Fabricio (orgs.), A Bolívia no espelho do futuro, UFMG, IUPERJ, Belo Horizonte, Rio de Janeiro.

Vitullo, Gabriel Eduardo (2012), As outras teorias da democracia. Participacionismo, deliberacionismo e republicanismo cívico, EDUFRN, Natal.

Recibido: 15.10.2013

Aceptado: 13.12.2013 